\title{
CrystEngComm
}

Check for updates

Cite this: CrystEngComm, 2020, 22, 8136

Received 22nd August 2020,

Accepted 2nd November 2020

DOI: $10.1039 / \mathrm{d} 0 \mathrm{ce} 01225 \mathrm{~d}$

rsc.li/crystengcomm

\section{Mutation of position 5 as a crystal engineering tool for a NIR-emitting DNA-stabilized $\mathbf{A g}_{16}$ nanocluster}

\author{
Cecilia Cerretani, (1D ${ }^{a}$ Jiro Kondo (D) ${ }^{* b}$ and Tom Vosch (D)*a
}

\begin{abstract}
Mutation of position 5 in a ten-base DNA sequence allowed us to probe its role in the photophysical and structural properties of a DNA-stabilized silver 16 nanocluster (DNA-Ag ${ }_{16} \mathrm{NC}$ ). A comparison of the original T5 (thymine at position 5) compound with the new modifications: X5 (abasic site), C5 (cytosine), A5 (adenine) and G5 (guanine), was made. All mutants were able to create a similar $\mathrm{Ag}_{16} \mathrm{NC}$ as formed by the original T5, however diverse packing of the crystal asymmetric units in the crystalline state and minor differences in the spectroscopic properties were observed. We showed that certain nucleotides are essential for stabilizing the $\mathrm{Ag}_{16} \mathrm{NC}$, while others are not critical and can be utilized for engineering the arrangement of the asymmetric units in the crystalline state. The latter opens up the possibility to extend the primary role of the DNA as a scaffold for encapsulating the AgNC to a secondary 3D crystal engineering tool.
\end{abstract}

\section{Introduction}

Despite their interesting fluorescence properties, ${ }^{1-7}$ only limited structural information is available for DNA-stabilized silver nanoclusters (DNA-AgNCs) ${ }^{8,9}$ DNA-AgNCs are usually composed of one or several DNA strands that encapsulate a precise number of silver atoms, ranging between 2 and $30 .{ }^{10-13}$ The spectroscopic properties of the DNA-AgNCs can be modified by changing the DNA nucleotide sequence. Screening of DNA sequences and machine-learning algorithms have assisted in recent years to discover a series of interesting DNA-AgNCs and started to unravel the intricate relationship of sequence versus the final photophysical properties of the encapsulated $\mathrm{AgNC}^{14-17}$ We recently reported the crystal structure of a $\mathrm{Ag}_{16} \mathrm{NC}$ that can be stabilized by either two 5'-CACCTAGCGA-3' strands (here referred to as $\mathrm{T} 5)^{9}$ or two shortened versions without the terminal adenosine: $5^{\prime}$-CACCTAGCG-3' (here referred to as $\left.\mathrm{T} 5-\mathrm{A}_{10}\right) .{ }^{18}$ An intriguing finding of these studies was that the thymine in position 5 is pointed outwards and does not

\footnotetext{
${ }^{a}$ Department of Chemistry, University of Copenhagen, Universitetsparken 5, Copenhagen 2100, Denmark.E-mail: tom@chem.ku.dk

${ }^{b}$ Department of Materials and Life Sciences, Sophia University, 7-1 Kioi-cho, Chiyoda-ku, 102-8554 Tokyo, Japan. E-mail: j.kondo@sophia.ac.jp

$\dagger$ Electronic supplementary information (ESI) available: Materials and methods section, HPLC purification information, 2D emission vs. excitation plots, fluorescence quantum yield calculations, hydrodynamic volume calculations, additional emission spectra, decay curves, average decay times, TRES, brightfield and fluorescence images of the crystals, subunit and crystal packing views, crystal data and collection statistics. See DOI: 10.1039/d0ce01225d
}

interact with the $\mathrm{Ag}_{16} \mathrm{NC}$. However, it seems to play a critical role in the crystallization process by facilitating interactions between neighboring DNA- $\mathrm{Ag}_{16} \mathrm{NCs}$ in the crystalline state. To investigate the role of the thymine in position 5 in more detail, we used DNA sequences where this thymine was exchanged with an adenine (A5), cytosine (C5), guanine (G5) and an abasic site (X5). The A5, X5, C5 formed similar nearinfrared (NIR) emitting $\mathrm{Ag}_{16} \mathrm{NCs}$, while the guanine mutant created two emitters that will be referred to as G5-NIR and G5-RED. Spectroscopic properties and structural information from single crystal X-ray diffraction were collected for A5, C5, X5 and G5-NIR. Structural and spectroscopic properties of the original T5 were published previously and used for comparison with the mutants here. ${ }^{9,19}$ To the best of our knowledge, this is the first time that site-specific mutation has been used to compare the effect on the spectroscopic and structural properties of a DNA-AgNC. The understanding gained here in this paper will hopefully allow us to modify the DNA sequences of other DNA-AgNCs in order to crystallize them and improve the structure/property relationship in this new class of emitters. We therefore identified nucleotides that are essential for stabilizing the AgNCs and others that promote crystal packing interactions.

\section{Results and discussion}

\section{Photophysical properties of the solution state}

DNA-Ag ${ }_{16}$ NCs using 5'-CACCRAGCGA-3' ( $\left.\mathrm{R}=\mathrm{X}, \mathrm{A}, \mathrm{C}, \mathrm{G}\right)$ were synthesized (for details, see ESI $\dagger$ ) and, after three days, HPLC-purified. HPLC chromatograms and details on the 

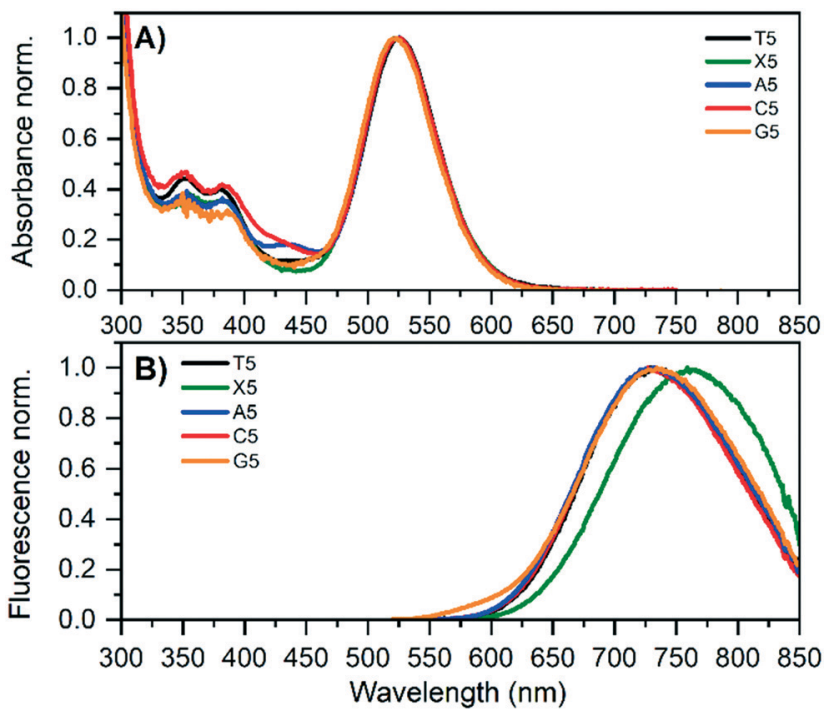

Fig. 1 Normalized absorption A) and emission B) spectra for the original $\mathrm{T5}$ and all mutants in $10 \mathrm{mM}$ ammonium acetate $\left(\mathrm{NH}_{4} \mathrm{OAc}\right)$. The emission spectra were acquired by exciting at $507.5 \mathrm{~nm}$ (LDH-PC-510).

collected fractions can be found in Fig. S1-S4.† Fig. 1 shows the absorption and emission spectra of the original $\mathrm{T} 5$ and the four mutants; X5, A5, C5 and G5. The main AgNC-related absorption peak around $525 \mathrm{~nm}$ is similar for all five compounds. All compounds show also absorption features in the 300 to $450 \mathrm{~nm}$ range that are similar but slightly different for each mutant. While X5, A5 and C5 are stable, the G5 compound has limited stability and G5-NIR converts over time to the red emitter G5-RED (see below). For all compounds, position 5 is bent outwards (see below) and this nucleotide does not interact with the $\mathrm{Ag}_{16} \mathrm{NC}$, indicating that this position has no significant effect on the main $\mathrm{Ag}_{16} \mathrm{NC}$ related optical transition. The emission spectra are very similar for T5, A5, C5 and G5-NIR. The only mutant with a slightly different emission spectrum is $\mathrm{X} 5$ which is redshifted about $25 \mathrm{~nm}$ compared to T5. All absorption and emission maxima values can be found in Table 1. The 2D excitation versus emission plots for $\mathrm{X} 5, \mathrm{~A} 5$ and $\mathrm{C} 5$ can be found in Fig. S5-S7. $\uparrow$ The quantum yields of fluorescence are also given in Table 1 and range from 0.19 to 0.31 (see Fig. S8-S10 $\dagger$ for details). The emission spectrum of G5 in Fig. 1B already indicates the presence of G5-RED by the additional blue tail on top of the G5-NIR emission.

Next, G5 was studied in more detail to obtain the solution state properties of both emitters. Fig. 2A shows the absorption and excitation spectra of a HPLC-purified G5 sample that was 2 days old. The $600 \mathrm{~nm}$ excitation spectrum probes mainly G5-RED and has an excitation maximum at $514 \mathrm{~nm}$, while the $730 \mathrm{~nm}$ excitation spectrum probes predominantly G5-NIR, whose excitation maximum is at 524 $\mathrm{nm}$. Interestingly, the absorption spectrum of the aged G5 solution (Fig. 2A) shows additional absorption features at 400 and $450 \mathrm{~nm}$ that were not present in the fresh G5 solution, indicating that besides the formation of G5-RED, other species are formed as well. To investigate that G5-RED is formed from G5-NIR, we heated the solution to accelerate the conversion. Gradual heating from $10{ }^{\circ} \mathrm{C}$ to $50{ }^{\circ} \mathrm{C}$ promotes the conversion, as can be seen in the emission spectra in Fig. 2B. Cooling down the G5 sample from $50{ }^{\circ} \mathrm{C}$ to $10^{\circ} \mathrm{C}$ did not reform G5-NIR, indicating that the conversion is irreversible (see Fig. S15†).

After characterizing the steady-state fluorescence properties, time-correlated single photon counting (TCSPC) measurements were performed. Table 1 shows the intensityaveraged decay times, weighted over the whole emission spectrum $\left\langle\tau_{\mathrm{w}}\right\rangle$ at different temperatures, and the hydrodynamic volumes, calculated from the time-resolved anisotropy experiments. The hydrodynamic volumes of the original T5 and the mutants (see Fig. S11-S13†) are similar in size, indicating that in solution the DNA-AgNCs are present as individual entities, and do not aggregate at the experimental solution concentrations. The largest difference between $\mathrm{T} 5$ and the mutants can be found in the fluorescence decay time. T5 and C5 have similar fluorescence decay times of $3.27 \mathrm{~ns}$ and $3.35 \mathrm{~ns}$ at $25^{\circ} \mathrm{C}$. X5, A5 and G5NIR have significantly lower decay times of $2.42 \mathrm{~ns}, 2.54 \mathrm{~ns}$ and $2.52 \mathrm{~ns}$, respectively. Plotting the quantum yield of fluorescence versus the fluorescence decay time (see Fig. S16†) results in a plot that can be fit linearly with a $(0,0)$

Table 1 Steady-state and time-resolved solution properties of T5 and all the mutants: absorption and emission maxima at RT, quantum yields ( $Q$ ), intensity-weighted average decay times, weighted by the steady-state intensity over the whole emission range $\left(\left\langle\tau_{\mathrm{w}}\right\rangle\right)$, at $5^{\circ} \mathrm{C}, 25^{\circ} \mathrm{C}$ and $40{ }^{\circ} \mathrm{C}$, and the hydrodynamic volumes $(V)$

\begin{tabular}{|c|c|c|c|c|c|c|c|}
\hline & Abs max (nm) & $\operatorname{Em} \max (\mathrm{nm})$ & $\left\langle\tau_{\mathrm{w}}\right\rangle 5^{\circ} \mathrm{C}(\mathrm{ns})$ & $\left\langle\tau_{\mathrm{w}}\right\rangle 25^{\circ} \mathrm{C}(\mathrm{ns})$ & $\left\langle\tau_{\mathrm{w}}\right\rangle 40^{\circ} \mathrm{C}(\mathrm{ns})$ & $V\left(\mathrm{~nm}^{3}\right)$ & $Q^{e} 25^{\circ} \mathrm{C}$ \\
\hline $\mathrm{T} 5^{a}$ & 525 & 736 & - & 3.27 & - & $10.32^{c}$ & 0.26 \\
\hline $\mathrm{X} 5$ & 524 & 761 & 3.07 & 2.42 & 1.93 & 10.27 & 0.19 \\
\hline A5 & 528 & 739 & 3.10 & 2.54 & 2.21 & 10.28 & 0.25 \\
\hline C5 & 530 & 735 & 3.82 & 3.35 & 2.87 & 10.30 & 0.31 \\
\hline G5-NIR & $524^{b}$ & 730 & $3.16^{d}$ & $2.52^{d}$ & $1.84^{d}$ & 10.22 & - \\
\hline G5-RED & $514^{b}$ & 610 & $1.33^{d}$ & $1.10^{d}$ & $0.77^{d}$ & - & - \\
\hline
\end{tabular}

${ }^{a}$ Data from Bogh et al. ${ }^{19}{ }^{b}$ Estimated from the excitation spectra. ${ }^{c}$ Data from Bogh et al. and re-analyzed in the same way as the mutants presented here. ${ }^{19} d$ Due to the spectral overlap of G5-NIR and G5-RED, these values are $\langle\tau\rangle$ values at $730 \mathrm{~nm}$ and $600 \mathrm{~nm}$ respectively. ${ }^{e}$ Reference was cresyl violet in absolute ethanol $(Q=0.56) .{ }^{22}-$ indicates that data was not measured. 

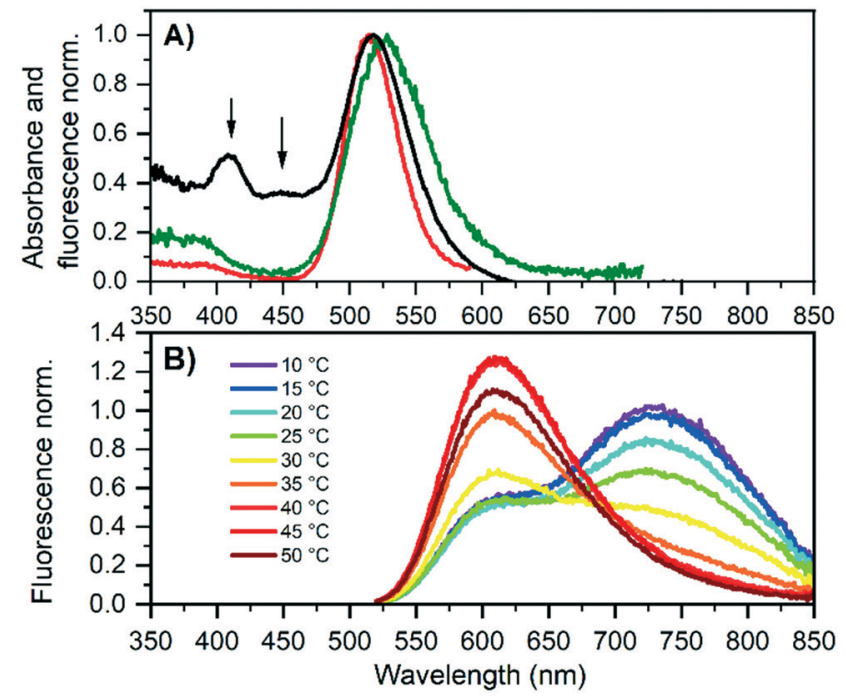

Fig. 2 A) Normalized absorption (black) and excitation (red and green) of $\mathrm{G} 5$ in $10 \mathrm{mM} \mathrm{NH}_{4} \mathrm{OAc} 2$ days after purification. The red and green excitation spectra were recorded by monitoring the emission at 600 $\mathrm{nm}$ and $730 \mathrm{~nm}$, respectively. B) Emission spectra corresponding to the first heating cycle of G5 $\left(\lambda_{\text {exc }}=507.5 \mathrm{~nm}\right)$, acquired two days after HPLC purification.

intersect. This could indicate that T5, X5, A5 and C5 have similar radiative rates and that the magnitude of the nonradiative decay pathways is dependent on the specific configuration at position 5. Since this position is pointed outwards and does not interact with the AgNC itself as explained below, we speculate that the local flexibility of this group could influence the rate of the non-radiative decay. As demonstrated previously for a number of other DNAAgNCs, ${ }^{20,21}$ slow spectral relaxation on the time-scale of the fluorescence decay time occurs and leads to multiexponential decay behavior at a specific wavelength (Fig. 3).

\section{Photophysical properties of the crystalline state}

Crystals of the mutants were grown, as T5, by the hangingdrop vapor-diffusion method at 293 K. However, every modification required a different crystallization condition.

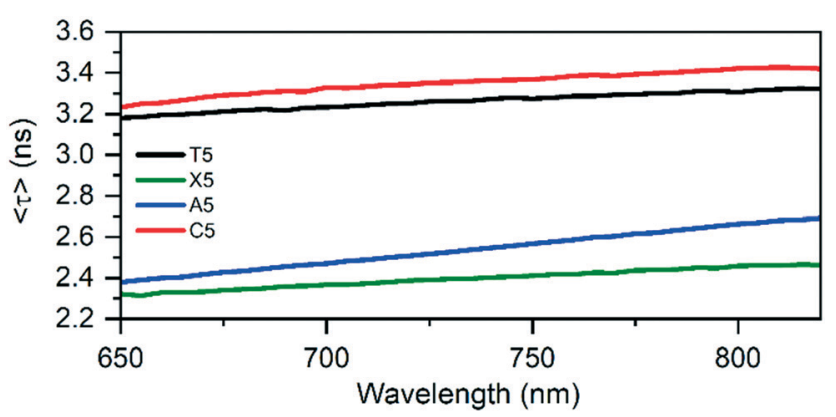

Fig. 3 Average decay times of the original T5, X5, A5, and C5 mutants as a function of the emission wavelength at $25^{\circ} \mathrm{C}$. T5 data was taken from Bogh et al. ${ }^{19}$
The specific conditions are described in the Materials and methods section of the ESI. $\dagger$ For G5, only fresh solution containing mostly G5-NIR could be crystallized. Attempts to crystallize heat-treated G5 solution that contain mainly G5RED (see Fig. 2B) were unsuccessful. Based on this and the crystal structure itself (see below), we can confidently conclude that only G5-NIR can be crystallized. Fig. 4 shows exemplary bright field and fluorescence images of A5 crystals, while Fig. S21-S24† show additional images of C5, X5, G5 and A5 crystals obtained with diverse crystallization conditions. Once the crystals were formed, fluorescence emission and decay time measurements were carried out to verify that the crystalline structure display similar photophysical properties as in solution. Emission maxima and $\left\langle\tau_{\mathrm{w}}\right\rangle$ of the crystals are listed in Table 2. All emission spectra of the crystalline state are blue-shifted compared to the solution case, which could be due to the crystal packing that reduces the DNA flexibility, and therefore limits the spectral relaxation. The magnitude of the blue-shift is likely

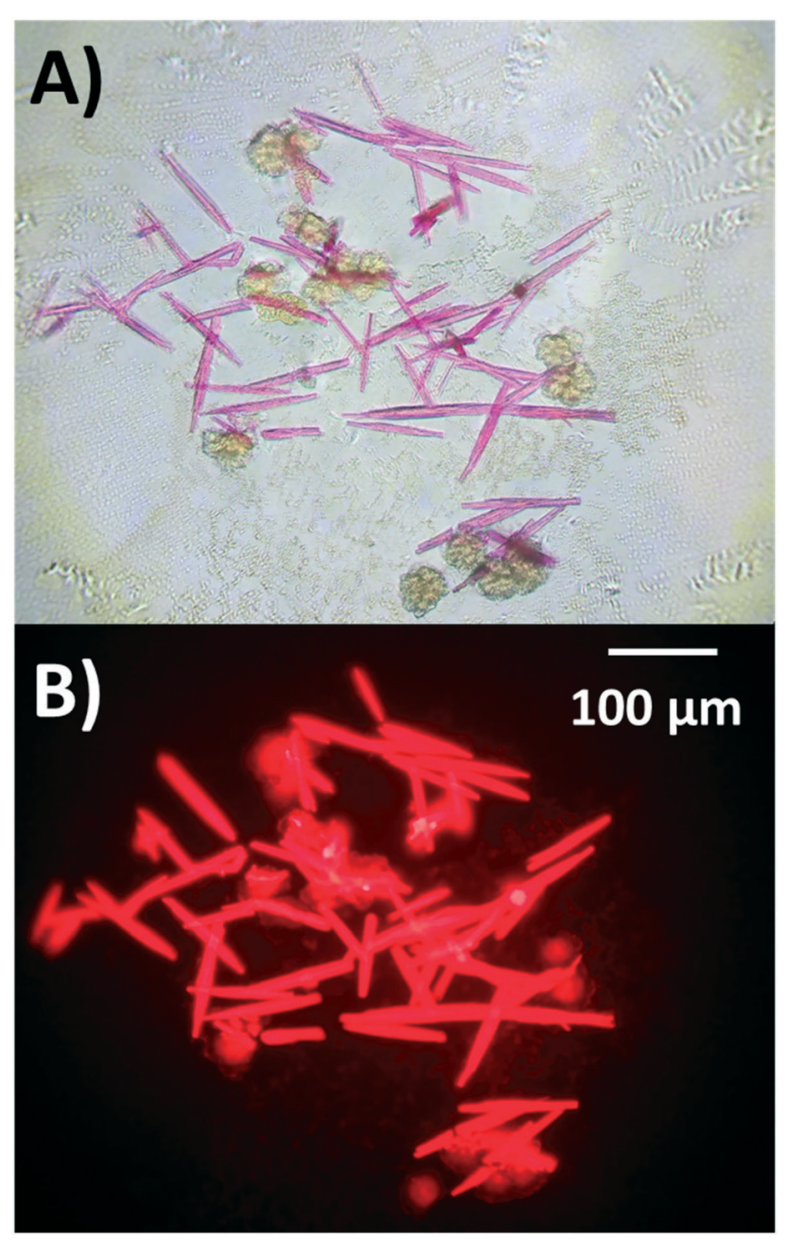

Fig. 4 A) Bright field and B) fluorescence images of $A 5$ crystals at $10 \times$ magnification. $1 \mu \mathrm{L}$ of $\mathrm{A} 5$ solution was mixed with $1 \mu \mathrm{L}$ of crystallization buffer composed of 10\% PEG, $10 \mathrm{mM}$ spermine, $50 \mathrm{mM}$ 3-( $N$-morpholino)propanesulfonic acid $(\mathrm{pH}=7)$ and $300 \mathrm{mM} \mathrm{Ca}\left(\mathrm{NO}_{3}\right)_{2}$. Additional images of all mutants can be found in the ESI $\dagger$ (Fig. S21S24). 
Table 2 Emission maxima and $\left\langle\tau_{\mathrm{w}}\right\rangle$ of the original T5 and the mutants in the crystalline state

\begin{tabular}{lll}
\hline & ${\operatorname{Em~} \max ^{a}(\mathrm{~nm})}$ & $\left\langle\tau_{\mathrm{w}}\right\rangle_{\mathrm{RT}}{ }^{a}(\mathrm{~ns})$ \\
\hline T5 & $711^{b}$ & $2.26^{c}$ \\
X5 & 715 & 1.68 \\
A5 & 671 & 2.26 \\
C5 & 703 & 2.64 \\
G5-NIR & 719 & 2.88
\end{tabular}

${ }^{a}$ All $\left\langle\tau_{\mathrm{w}}\right\rangle$ values (except for T5) and emission maxima are the average of five different crystals/crystal positions measurements. ${ }^{b}$ Calculated from the data by Cerretani et $a l .{ }^{9}{ }^{c}$ Single value measurement only, taken from Cerretani et al. ${ }^{9}$

dependent on the arrangement of the asymmetric units in the crystals.

\section{Crystal structure}

Crystal structures of A5, C5, G5-NIR and X5 can be found on the PDB website with accession codes 7BSE, 7BSF, 7BSG, and 7BSH, respectively. The structure of the subunits (subunit refers here to the $\mathrm{Ag}_{16} \mathrm{NC}$ stabilized by two stands of DNA, see Fig. 5) of the different mutants is similar to the original T5 (accession code 6JR4), where every $\mathrm{Ag}_{16} \mathrm{NC}$ is formed by $16 \mathrm{Ag}$ atoms with occupancy of 1 , and two additional $\mathrm{Ag}$ atoms with occupancy around 0.3. The latter Ag atoms are the only two that do not directly interact with any bases. This could explain the occupancy below 1, as the lack of direct bonding to a base introduces potential disorder. It could mean that the AgNC is in fact a $\mathrm{Ag}_{18} \mathrm{NC}$, although this is still speculative at this point. Therefore, we continue to refer to the $\mathrm{AgNC}$ as $\mathrm{Ag}_{16} \mathrm{NC}$.

Every $\mathrm{Ag}_{16} \mathrm{NC}$ is stabilized by two DNA strands with a roughly similar conformation as $\mathrm{T} 5$, with the exception of the $3^{\prime}$ end $\mathrm{A}_{10}$ adenosines (see Fig. 5C) that differ significantly. As shown in Fig. 5B, position 5 always points outwards and there are no interactions between any of the position 5 nucleotides and the $\mathrm{Ag}$ atoms. In the G5-NIR structure, one $\mathrm{G}_{5}$ and one $\mathrm{A}_{10}$ base are disordered and cannot be seen in the structure. Individual views of each mutant can be found in Fig. S33-S37. $\mathrm{No}^{+} \mathrm{Ag}^{+}$-mediated interactions of the $\mathrm{A}_{10}$ bases were found in the mutants. This is in contrast to the original $\mathrm{T} 5$, where two $\mathrm{A}_{10}$ bases from neighboring unit cells formed a $\mathrm{Ag}^{+}$-mediated bond with an occupancy $\sim 0.3$. Recently, we demonstrated for a T5 mutant without the terminal $\mathrm{A}_{10}\left(\mathrm{~T} 5-\mathrm{A}_{10}\right.$, accession code $\left.6 \mathrm{M} 2 \mathrm{P}\right)$ that this $\mathrm{Ag}^{+}$mediated bond between two $\mathrm{A}_{10}$ bases is not critical for the formation and stabilization of the crystal structure since T5$\mathrm{A}_{10}$ and $\mathrm{T} 5$ form isomorphous crystals with almost identical unit cell parameters. Besides positions 10 and 5, some variations can also be seen in position 2 for one of the $\mathrm{A}_{2}$ bases. While $\mathrm{A}_{2} \mathrm{~S}$ of the $\mathrm{C} 5$ mutant and the original $\mathrm{T} 5$ overlap, X5, G5 and A5 have a different position for one of the $\mathrm{A}_{2} \mathrm{~S}$ (see Fig. $5 \mathrm{~A}$ ).

The X5 and C5 crystals share the same orthorhombic space group with one subunit in the asymmetric unit. The

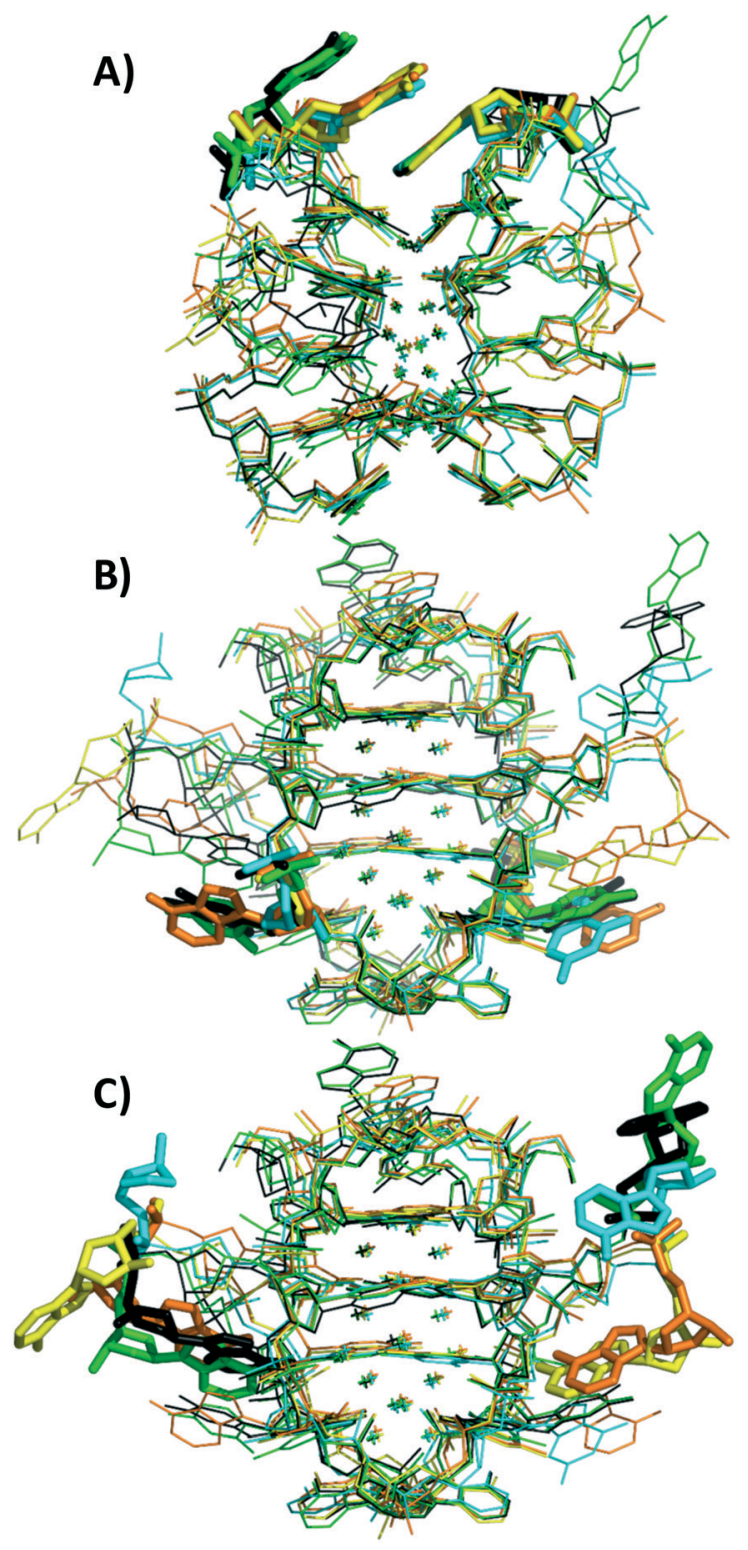

Fig. 5 Superimposition of the original T5 (black) subunit and the four new mutants: A5 (orange), C5 (green), G5 (cyan) and X5 (yellow). A) Highlights the differences at position 2, while B) highlights the differences at position 5, and C) highlights the differences at position 10 .

G5-NIR crystal is also orthorhombic with one subunit in the asymmetric unit, but has a different space group. On the other hand, A5 is tetragonal and contains two subunits in the asymmetric unit. All space groups of the mutants differ from the original $\mathrm{T} 5$ that was found to be monoclinic with two subunits in the asymmetric unit. Unlike A5 and G5-NIR, the crystal structures of $\mathrm{X} 5$ and $\mathrm{C} 5$ were refined to higher resolutions of $1.2 \AA$ and $1.1 \AA$, which allowed to include the hydrogen atoms. Further details can be found in Tables S3 and $\mathrm{S} 4 . \dagger \mathrm{Ca}^{2+}$ ions could be observed between the subunits of the A5 structure but not between neighboring asymmetric units (see Fig. S38†), most likely due to the larger distance (making the ions disordered). A single $\mathrm{Ca}^{2+}$ is also present in the structure of the $\mathrm{C} 5$ mutant between two asymmetric units 

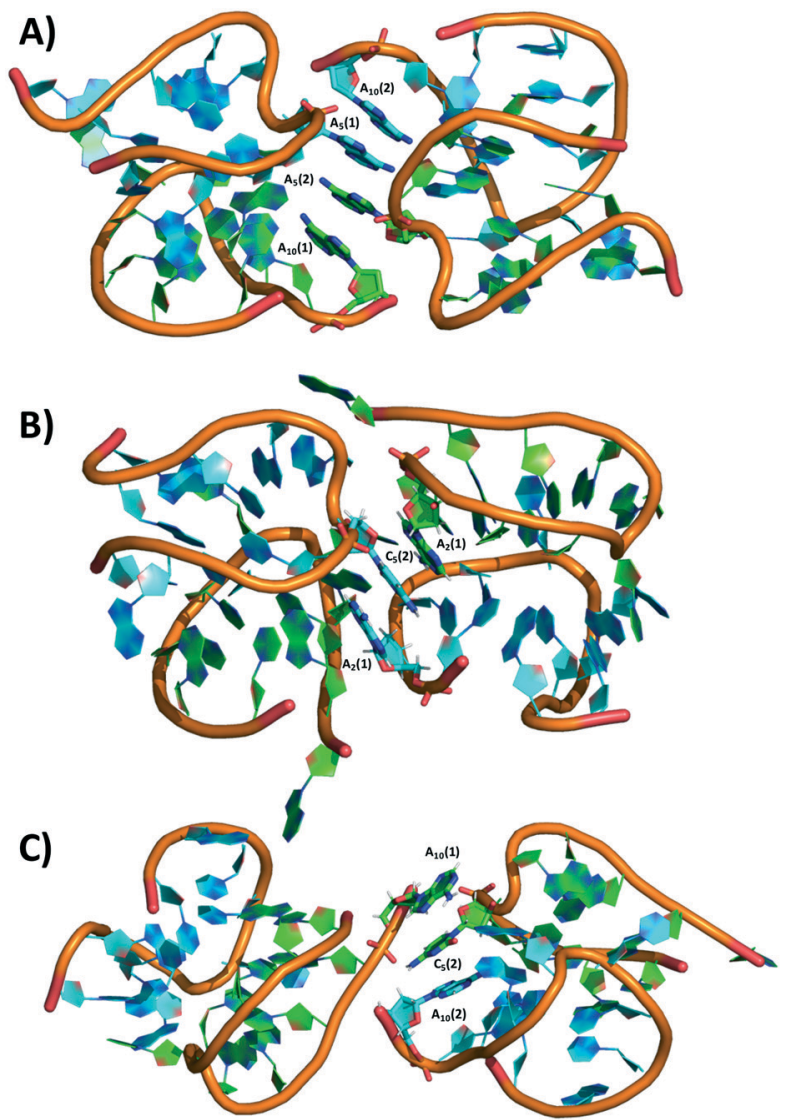

Fig. $6 \pi-\pi$ stacking interactions in A) A5 and B, C) C5. Silver and calcium atoms are omitted for clarity.

(see Fig. S39†). However, it is reasonable to assume that all mutant structures contain a certain number of $\mathrm{Ca}^{2+}$ ions to compensate the negative charge of the phosphate backbone, but they are disordered in the structure.

Regarding the crystal packing, many diverse $\pi-\pi$ stacking interactions were found between nucleotide bases of different asymmetric units. These different $\pi-\pi$ stacking seem to drive the final packing of the crystals. The G5-NIR crystal contains intermolecular $\mathrm{G}_{5}-\mathrm{A}_{10}$ and $\mathrm{A}_{2}-\mathrm{A}_{2}$ interactions between neighboring molecules, while for the $\mathrm{X} 5$ crystal, intermolecular $\mathrm{A}_{10}-\mathrm{A}_{2}$ interactions are found. The $\mathrm{A} 5$ crystal has intermolecular interactions between $A_{6}$ and $A_{10}$. Additionally, an interesting interaction between two $\mathrm{A}_{10} \mathrm{~S}$ and two $A_{5} \mathrm{~S}: \mathrm{A}_{10}(1)-\mathrm{A}_{5}(2)-\mathrm{A}_{5}(1)-\mathrm{A}_{10}(2)$, where 1 and 2 within brackets indicate different asymmetric units, can be found. This interaction can be seen in Fig. 6A. In the C5 crystal, triple base interactions can be seen between $A_{2}(1)-C_{5}(2)-A_{2}(1)$ and $A_{10}(1)-C_{5}(2)-A_{10}(2)$, as shown in Fig. $6 B$ and C. It seems that these positions (2, 5 and 10$)$, although less critical to the AgNC stabilization, can play important roles in the crystal packing, and allow to manipulate the orientation of the AgNCs with respect to each other (see Fig. S38-S41† for an overview of the different asymmetric unit packing in the mutants). These base $\pi-\pi$ stacking interactions can therefore become an important tool for creating specific crystal structures where the AgNCs can be positioned with designed orientations with respect to each other.

Recently, Copp et al. used machine learning tools in order to find stabilizing motifs able to produce specific emissive AgNCs. ${ }^{23}$ Our finding on the different mutants presented here, together with the $\mathrm{T}^{-}-\mathrm{A}_{10}$ findings,${ }^{18}$ allowed to investigate this idea of a minimal motif needed to stabilize a specific AgNC. However, what matters is not necessarily the $5^{\prime}-3^{\prime}$ arrangement of the oligonucleotides, but their 3D position. Additionally, for small DNA sequences, it seems common that two strands are involved in stabilizing the AgNC, adding an additional level of motif complexity. In our case, we propose a minimum pattern $5^{\prime}$-CACC/AGCG/-3', responsible for stabilizing the $\mathrm{Ag}_{16} \mathrm{NC}$, while positions 5 and 10 and partially position 2 (only one of the two strands) are of lesser importance. Cerretani et al. demonstrated recently that $\mathrm{A}_{10}$ can be removed with no significant consequences on the photophysical and structural properties. ${ }^{18}$ Besides using bases that do not interact with the AgNC to control crystal packing, it is also reasonable to assume that changing the crystallization conditions could be a way to force the asymmetric units in different packing geometries.

\section{Conclusions}

Mutation of position 5 enabled us to investigate its importance on the spectroscopic properties and crystal structure. Overall, mutating the 5 position with a cytosine (C5), guanine (G5), adenine (A5) or an abasic site (X5) still allowed us to create a NIR emitter and crystallize a similar $\mathrm{Ag}_{16} \mathrm{NC}$ as the original $\mathrm{T} 5$ compound. The only divergent behavior was for the G5 mutant that besides a G5-NIR also formed a G5-RED emitter. The G5-RED population could be enhanced by heating the G5-NIR solution. While we have shown here that the actual base at position 5 causes only minor changes to the photophysical properties of the $\mathrm{Ag}_{16} \mathrm{NC}$ emitter and even less to its structure, its backbone performs a critical role in providing the needed flexibility for the DNA to fold around the $\mathrm{Ag}_{16} \mathrm{NC}$. Additionally, analyzing the crystal packing of the different mutants showed that positions 2, 5 and 10 can be used to drive the stacking of different asymmetric units in the crystal. We concluded that, based on the presented finding, a minimal pattern of 5 -CACC/AGCG/$3^{\prime}$ is needed to produce the $\mathrm{Ag}_{16} \mathrm{NC}$ with the two additional $\sim 0.3$ occupancy $\mathrm{Ag}$ atoms. Our results provide also an approach to crystallize DNA-AgNCs that currently cannot be crystallized. Mutating non-critical nucleotides, not involved in direct binding to the AgNC, can induce $\pi-\pi$ stacking interactions between different units and drive crystallization. Additionally, being able to potentially align AgNCs could create crystals with interesting polarization properties.

\section{Conflicts of interest}

There are no conflicts to declare. 


\section{Acknowledgements}

C. C. and T. V. gratefully acknowledge financial support from the Villum Foundation (Project number VKR023115). J. K. was supported by Grant-in-Aid for Scientific Research (B) (No. 17H03033). We thank the Photon Factory (Tsukuba, Japan) for access to the synchrotron radiation facilities (No. 2019G539).

\section{Notes and references}

1 I. L. Volkov, Z. V. Reveguk, P. Y. Serdobintsev, R. R. Ramazanov and A. I. Kononov, Nucleic Acids Res., 2018, 46, 3543-3551.

2 I. L. Volkov, P. Y. Serdobintsev and A. I. Kononov, J. Phys. Chem. C, 2013, 117, 24079-24083.

3 J. M. Obliosca, C. Liu and H. C. Yeh, Nanoscale, 2013, 5, 8443-8461.

4 P. R. Oneill, E. G. Gwinn and D. K. Fygenson, J. Phys. Chem. C, 2011, 115, 24061-24066.

5 S. H. Yau, N. Abeyasinghe, M. Orr, L. Upton, O. Varnavski, J. H. Werner, H. C. Yeh, J. Sharma, A. P. Shreve, J. S. Martinez and T. Goodson Iii, Nanoscale, 2012, 4, 4247-4254.

6 H. C. Hsu, Y. X. Lin and C. W. Chang, Dyes Pigm., 2017, 146, 420-424.

7 J. T. Petty, J. Zheng, N. V. Hud and R. M. Dickson, J. Am. Chem. Soc., 2004, 126, 5207-5212.

8 D. J. E. Huard, A. Demissie, D. Kim, D. Lewis, R. M. Dickson, J. T. Petty and R. L. Lieberman, J. Am. Chem. Soc., 2019, 141, 11465-11470.

9 C. Cerretani, H. Kanazawa, T. Vosch and J. Kondo, Angew. Chem., Int. Ed., 2019, 58, 17153-17157.
10 D. Schultz and E. G. Gwinn, Chem. Commun., 2012, 48, 5748-5750.

11 E. Gwinn, D. Schultz, S. M. Copp and S. Swasey, Nanomaterials, 2014, 5, 180-207.

12 E. G. Gwinn, P. O'Neill, A. J. Guerrero, D. Bouwmeester and D. K. Fygenson, Adv. Mater., 2008, 20, 279-283.

13 Z.-G. Wang, Q. Liu, N. Li and B. Ding, Chem. Mater, 2016, 28, 8834-8841.

14 C. I. Richards, S. Choi, J. C. Hsiang, Y. Antoku, T. Vosch, A. Bongiorno, Y. L. Tzeng and R. M. Dickson, J. Am. Chem. Soc., 2008, 130, 5038-5039.

15 S. M. Copp, A. Gorovits, S. M. Swasey, S. Gudibandi, P. Bogdanov and E. G. Gwinn, ACS Nano, 2018, 12, 8240-8247.

16 S. M. Copp, D. Schultz, S. Swasey, J. Pavlovich, M. Debord, A. Chiu, K. Olsson and E. Gwinn, J. Phys. Chem. Lett., 2014, 5, 959-963.

17 S. M. Copp, S. M. Swasey, A. Gorovits, P. Bogdanov and E. G. Gwinn, Chem. Mater., 2020, 32, 430-437.

18 C. Cerretani, J. Kondo and T. Vosch, RSC Adv., 2020, 10, 23854-23860.

19 S. A. Bogh, M. R. Carro-Temboury, C. Cerretani, S. M. Swasey, S. M. Copp, E. G. Gwinn and T. Vosch, Methods Appl. Fluoresc., 2018, 6, 024004.

20 C. Cerretani, M. R. Carro-Temboury, S. Krause, S. A. Bogh and T. Vosch, Chem. Commun., 2017, 53, 12556-12559.

21 S. A. Bogh, C. Cerretani, L. Kacenauskaite, M. R. CarroTemboury and T. Vosch, ACS Omega, 2017, 2, 4657-4664.

22 A. M. Brouwer, Pure Appl. Chem., 2011, 83, 2213.

23 S. M. Copp, P. Bogdanov, M. Debord, A. Singh and E. Gwinn, Adv. Mater., 2014, 26, 5839-5845. 